showed a slight increase in prevalence $(\mathrm{P}<0.042)$. The frequency of developmental delay, brain abnormalities, and congenital heart defect was not significant.

Sotos syndrome is a genetic disorder caused by NSD1 mutations or deletions. The diagnosis is based on two major clinical criteria, a typical facial gestalt and macrocephaly. Advanced bone age, height, and learning difficulties are not specific for Sotos syndrome, and occur in other overgrowth syndromes. (Leventopoulos G, Kitsiou-Tzeli S, Kritikos K, et al. A clinical study of Sotos syndrome patients with review of the literature. Pediatr Neurol May 2009;40:357-364). (Respond: Dr Leventopoulos, Fokidos 53, Goudi, Athens 11527, Greece. E-mail: levent2669@,hotmail.com).

COMMENT. Sotos syndrome, or cerebral gigantism, was originally described as a syndrome of excessively rapid growth with acromegalic features and a non-progressive neurologic disorder (Sotos JF et al. N Engl J Med 1964;27:109-116). In early childhood, head circumference and height are $>97^{\text {th }}$ percentile, but after puberty, growth is normal. Neurologic defects include hypotonia, gait dyspraxia, developmental delay, mild mental retardation, and seizures, 50\% febrile. NSD1 mutations, frequent in European-origin patients, and microdeletions, in Japanese, account for genotype-phenotype differences involving prevalence of overgrowth, and cardiovascular and urogenital malformations. (Nagai T et al. J Med Genet 2003;40:285-289). Clinically, the diagnosis of Sotos syndrome should be suspected in children born with typical facial features and macrocephaly, especially if these cardinal manifestations are associated with excessive growth, advanced bone age, mental retardation, congenital heart defect, or genitourinary anomaly.

\title{
DEVELOPMENTAL COORDINATION DISORDER IN SCHOOL-AGE CHILDREN
}

The prevalence of developmental coordination disorder (DCD) in children, at 7 years of age, in a large UK birth cohort was determined using DSM-IV criteria, in a study at the University of Bristol, UK; and Utrecht University, Netherlands. Children with neurologic disorders or IQ of $<70$ were excluded. By using tests that measured manual dexterity, ball skills, balance, handwriting skills and activities of daily living, 119 of 6990 children met criteria for DCD, with a prevalence of $1.7 \%, 17 / 1000$ at a mean age of 7.5 years. The gender ratio was 1.8:1 male to female. When an additional 222 children with "probable DCD" were included, the risk of DCD was $4.9 \%$. The risk of DCD was greater in children of lower socioeconomic backgrounds, birth weight $<2500 \mathrm{~g}$, and born at $<37$ weeks' gestation. DCD is an important often overlooked cause of disability in school age children. (Lingham R, Hunt L, Golding J, Jongmans M, Emond A. Prevalence of developmental coordination disorder using the DSM-IV at 7 years of age: a UK population-based study. Pediatrics April 2009;123:e693-e700). (Respond: Raghu Lingam MBChB, MRCPCH, University of Bristol, Dept Community-Based Medicine, Bristol B566JS, UK. E-mail: raghu.lingam@bristol.ac.uk).

COMMENT. A similar study using different measures of coordination was conducted in apparently normal schoolchildren born extremely preterm $(<29$ weeks or birth weight $<1000$ g) at Westmead Hospital, New South Wales, Sydney, Australia. (Goyen T-A, Lui K. Arch Dis Child April 2009;94:298-302). At age 8 years, the prevalence of DCD was $42 \%$ in 
this high-risk population compared with $8 \%$ for matched classroom full-term controls. Motor assessment at 3 years of age using Peabody Fine Motor Scales is highly predictive of subsequent DCD at school age. Early identification of DCD allows early intervention to prevent school problems and loss of self-esteem. Differences in the prevalence rates of DCD in various reports could be explained by different methods of measurement. The incidence of ADHD, commonly complicated by DCD, in these cohorts would be of interest.

\section{PRESENTING SYMPTOMS OF CHIARI TYPE I MALFORMATION}

Clinical and radiographic predictors of neurologic symptoms were investigated in a population-based retrospective study of 51 children identified with Chiari I malformation at the University of California, and Kaiser Department of Radiology, San Francisco. The patients represented $1 \%$ of children who had head or spine MRI during the study period, 1997-1998. The mean age at diagnosis was 11 years. Tonsillar ectopia ranged from 5 to 32 $\mathrm{mm} ; 22 \%$ were $>10 \mathrm{~mm}$. Cerebellar tonsils were abnormally pointed in $55 \%$ of cases, with CSF compression in $57 \%$. Syringomyelia occurred in $6(12 \%)$ of the Chiari I patients. Nineteen (37\%) patients were diagnosed incidentally, MRIs performed for atypical symptoms such as seizures and scoliosis.

Of the 51 patients, $32(63 \%)$ had symptoms at diagnosis. Headache was the most common presenting complaint, occurring in $28(55 \%)$ patients, neck pain in $12 \%$, vertigo $(8 \%)$, sensory changes $(6 \%)$, and ataxia or incoordination $(6 \%)$. Other symptoms at time of diagnosis included leg weakness, tinnitus, hearing loss, dysarthria, loss of consciousness and scoliosis with syrinx, each occurring in 1 patient. Patients were followed for a mean of 6.4 years, and headache was the most common complaint, occurring in $61 \%$ of the 51 patients during the study period. Headache was moderate or severe and required frequent follow-up. Of 3 who had suboccipital decompression surgery for intractable daily headaches, 2 had complete resolution for up to 7 years of follow-up, and 1 relapsed after 12 months.

Older age at diagnosis was predictive of headache occurrence, while none of the radiological characteristics, including degree of ectopia, were associated with headache or other neurologic symptoms. Half of all children with Chiari I (49\%) had significant neurologic symptoms. Borderline tonsillar ectopia $(2-4 \mathrm{~mm})$, in 19 patients $(0.4 \%$ of all head and spine MRIs), although considered a normal variant, was associated with headache in $74 \%$, severe in $16 \%$. Occipital headache occurred in $11 \%$. None of the borderline cases showed pointed tonsils or retrocerebellar CSF compression $(\mathrm{P}<0.0001)$. (Aitken LA, Lindan $\mathrm{CE}$, Sidney S, et al. Chiari type I malformation in a pediatric population. Pediatr Neurol June 2009;40:449-454). (Respond: Dr Wu, UCSF Division of Child Neurology, 350 Parnassus, Suite 609, San Francisco, CA 94117. E-mail: wuy@neuropeds.ucsf.edu).

COMMENT. Headache is a frequent presenting symptom of Chiari I malformation in children, but the malformation is often discovered incidentally in children without characteristic symptoms. Although $5 \mathrm{~mm}$ of tonsillar ectopia is the accepted cutoff for the diagnosis of Chiari I, patients with lesser degrees of ectopia may also develop typical symptoms and syringomyelia. 